\title{
Isobaric Combustion for High Efficiency in an Optical Diesel Engine
}

\author{
Author, co-author (Do NOT enter this information. It will be pulled from participant tab in \\ MyTechZone) \\ Affiliation (Do NOT enter this information. It will be pulled from participant tab in MyTechZone)
}

\begin{abstract}
Isobaric combustion has been proven a promising strategy for high efficiency as well as low nitrogen oxides emissions, particularly in heavy-duty Diesel engines. Previous single-cylinder research engine experiments have, however, shown high soot levels when operating isobaric combustion. The combustion itself and the emissions formation with this combustion mode are not well understood due to the complexity of multiple injections strategy. Therefore, experiments with an equivalent heavy-duty Diesel optical engine were performed in this study. Three different cases were compared, an isochoric heat release case and two isobaric heat release cases. One of the isobaric cases was boosted to reach the maximum in-cylinder pressure of the isochoric one. The second isobaric case kept the same boost levels as the isochoric case. Results showed that in the isobaric cases, liquid fuel was injected into burning gases. This resulted in shorter ignition delays and thus a poor mixing level. The lack of fuel/air mixing was clearly the main contributor to the high soot emissions observed in isobaric combustion. The lower heat losses of the isobaric strategy were further explained by tracking the chemiluminescence. Unlike a long single injection, multiple injections helped to contain the hot gases away from the walls. However, the opposite effects were also found from the high thermal radiation caused by the extensive soot formation. Highpressure fluctuations from the rapid heat release of the isochoric case were further seen. Finally, better mixing for improved air utilization was deemed needed when utilizing isobaric heat release.
\end{abstract}

\section{Introduction}

Modern Diesel engines face increasingly stringent emission regulations, particularly for NOx, particulate matter and $\mathrm{CO}_{2}$. However, a trade-off between these three emissions exists [1]. Low NOx levels are achieved when using a lower in-cylinder temperature and a higher air-fuel ratio. However, for low $\mathrm{CO}_{2}$ emissions, higher efficiency is needed. Higher efficiency can be achieved by an increased in-cylinder temperature, at least for an ideal cycle. Thus, a NOxefficiency trade-off exists. Soot is formed when there are low local airfuel ratios and soot oxidation reduces at lower temperatures [2]. Thus, when avoiding NOx in Diesel engine operation, soot becomes a potential problem.

A number of solutions have been suggested for dealing with the NOxsoot-efficiency trade-off, including homogenous charge compression ignition (HCCI) [3, 4]. This concept, based on low-temperature combustion (LTC) chemistry, has reported low NOx emissions [5]. However, it still faces many challenges to control the combustion phasing and speed [6], which limit its use at low loads.

Page 1 of 10
Other concepts try to utilize the chamber air volume in a better way by enhancing the mixing. For instance, multiple injectors concepts, where two or three injectors are used [7, 8], have demonstrated lower heat losses as hot combustion gases are kept away from the cylinder walls with this strategy $[9,10]$. The multiple-injector concept is reported to directly increase engine efficiency by $1.9 \%$-points [10]. However, further efficiency increases are possible. Similarly, the enhanced mixing by an increased number of injector holes is reported to decrease soot and NOx levels in addition to reduced heat losses [11]. Thus, this concept diminishes the NOx-soot-efficiency trade-off.

The Double Compression Expansion Engine (DCEE) $[12,13]$ is a concept that utilizes a split-cycle approach where the cycle is divided between two units (see Figure 1). First, the low-pressure (LP) cylinder compresses ambient air. This air is then transferred to the highpressure (HP) cylinder for a second compression. This doublecompression approach allows high boosting that can lead to high peak pressures up to 300 bar [13]. Fuel is injected into this high-density air where it auto-ignites and burns during the expansion stroke. The hot exhaust gases are then transferred to the LP-cylinder for a second expansion, which allows recovery of the exhaust energy. The higher expansion ratio and the high-pressure combustion of this concept are the key parameters for improved efficiency. Brake efficiencies of up to $56 \%$ [14], as well as fuel flexibility [15], have been reported for the DCEE.

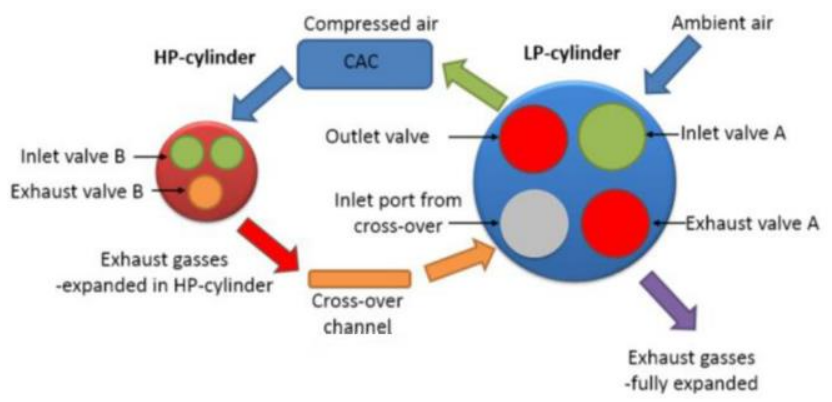

Figure 1, The DCEE concept layout [14]

Toward higher engine efficiency, the need for an optimized combustion process becomes increasingly important. Especially for the DCEE where high pressures are utilized. Traditionally, the isochoric heat release is labeled the upper limit of engine efficiency [16]. However, when considering the heat and friction losses, an isobaric heat release may have a higher efficiency [17]. 
For an isochoric heat release, the temperature rises rapidly leading to higher heat losses. Friction losses in engines also increase when reaching higher in-cylinder pressures [18]. Thus, the high peak pressure of isochoric heat release is not suitable for DCEE operation, particularly at high loads where pressures are high.

The optimum heat release for the DCEE concept has been previously investigated [19], where isochoric and isobaric heat releases were compared using one-dimensional GT Power simulations. The isobaric heat release utilized a higher compression ratio to reach the same peak pressure as the isochoric heat release. Results showed small differences in brake efficiency between the two types of heat release. However, the comparison was made at a constant heat multiplier value, leading to uncertainties in the heat transfer losses.

Other studies have suggested the potential of isobaric combustion in terms of high efficiency and low emissions [20]. In [20], the isobaric and conventional diesel combustions were compared. Conclusions showed similar efficiencies while, in isobaric combustion, NOx levels were diminished by $50 \%$, heat transfer losses reduced while exhaust energy and soot emissions increased. For the conventional diesel case, high pressure fluctuations were observed compared to the isobaric combustion, suggesting lower noise levels for isobaric cases.

So far, efficiency experiments were performed in a metal singlecylinder research engine where the interpretation of results was made based on hypotheses that need to be confirmed and demonstrated. In the current study, similar experiments are performed in an optical engine with identical geometry. High-speed chemiluminescence was recorded and used to give better insight on the isobaric combustion behavior in comparison to a conventional mode. The study sheds light on spray-to-spray interaction and its impact on soot formation and heat losses.

\section{Methodology}

\section{Engine Setup}

All experiments were conducted in a customized Volvo D13 C500 engine (see Figure 2). A single-cylinder approach was made by disconnecting five out of six cylinders by disabling the valves. The intake was fed by air at a temperature set by the heater mounted in the intake line. The air pressure was adjusted by a regulator, installed upstream of the engine intake line and connected to an external air compressor.

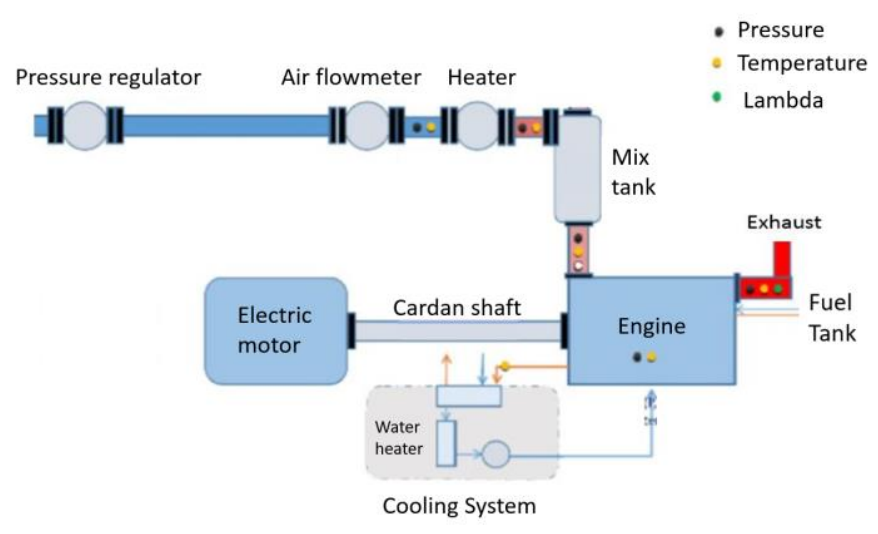

Figure 2, Engine test cell layout

Page 2 of 10
A mixing tank was placed after the air heater to damp the pressure acoustic oscillations during the intake valve opening time. An electric motor was used for controlling the engine speed. All experiments were performed at $1200 \mathrm{rpm}$. Details about engine geometry and specifications are reported in Table 1. A common rail system utilizing a Delphi pumping injector for pressure build-up was used for the fuel injection system. The injection pressure for all cases was kept at 1500 bar.

Table 1, Engine specifications

\begin{tabular}{|l|l|}
\hline Base Engine Configuration & Single cylinder/4 stroke \\
\hline Displacement Volume & $2.13 \mathrm{~L}$ \\
\hline Engine Speed & $1200 \mathrm{rpm}$ \\
\hline Stroke & $158 \mathrm{~mm}$ \\
\hline Bore & $131 \mathrm{~mm}$ \\
\hline Connecting Rod & $255 \mathrm{~mm}$ \\
\hline Effective Compression Ratio & $12.5: 1$ \\
\hline Cam/Valve Configuration & 4 valves per cylinder \\
\hline Fuel Injection System & Common rail(2700 bar max P) \\
\hline
\end{tabular}

\section{Earlier Metal Engine Experiments}

The optical engine study in this article is built upon earlier metal engine experiments [20]. With a compression ratio of $17: 1$, as compared to the 12.5:1 of the optical engine, a lower boost pressure and no heating was used. Other metal engine parameters coincide with the engine used in this study, described above. However, engine out emissions were measured in the metal engine setup.

The cases tested in the metal engine study were as follows:

- Conventional Diesel Combustion (CDC) - Typical CI combustion with a motored maximum pressure of 50 bar reaching a fired maximum pressure of 68 bar.

- Isobaric L - Isobaric heat release at 50 bar maximum incylinder pressure.

- Isobaric $\mathrm{H}$ - A higher boost pressure of 1.45 bar utilized to reach a maximum in-cylinder pressure of 68 bar followed by an isobaric heat release.

\section{Optical Approach}

For the optical engine, an extension was mounted on one of the metal pistons (see Figure 3). On this extension, a quartz piston was installed to allow optical access from the bottom view. The standard cylinder head together with a customized liner formed the optical combustion chamber. A Photron SA-X2 fast camera was mounted in front of a mirror placed below the optical piston to record the combustion chemiluminescence from the bottom view of the combustion chamber at a frame rate of $75 \mathrm{k}$ fps (see Figure 4). 


\begin{tabular}{|c|c|}
\hline Frame Rate [fps] & 75000 \\
\hline Frames per CAD & 10.42 \\
\hline Shutter Speed [s] & $1 / 400000$ \\
\hline Narrow-Pass Filter [nm] & $440 / 50$ \\
\hline Camera Trigger Point [CAD ATDC] & -4 \\
\hline
\end{tabular}

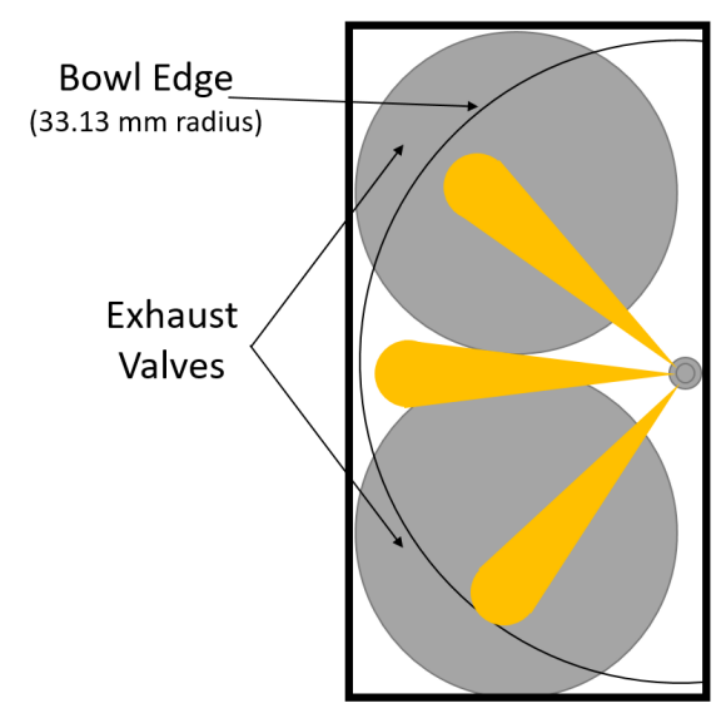

The camera settings are reminded in Table 2. A narrow-pass filter was utilized for all experimental cases allowing a range of $50 \mathrm{~nm}$ centered at $440 \mathrm{~nm}$ to pass. The reason for this is the high luminosity levels reached with the extensive soot radiation for certain cases. The use of a filter improved the quality of the optical images, which allowed a comprehensive study of multiple injections phenomena. To reach a higher frame rate, the region of interest was limited to only half of the combustion chamber (see Figure 4).

A skip-fire function was utilized for the optical engine. Three fired cycles were followed by ten motored cycles to reduce temperature stress on the optical parts. To avoid cycle-to-cycle variations, only the third cycle in every fired segment was studied. Regarding the statistical analysis of high-speed imaging, a filtration method was used. A median filter was applied to images in order to reduce the noise.

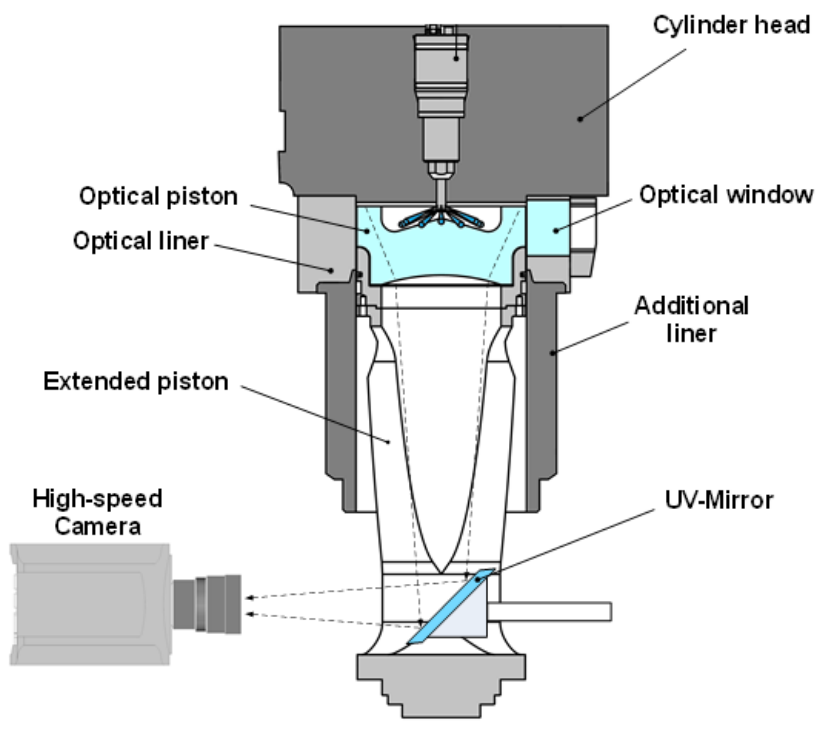

Figure 3, Optical extension of the engine allowing two-dimensional bottom-view through the piston

Page 3 of 10

Figure 4, Optical vision field as seen from below with a resolution of $256 * 480$ pixels

\section{Experimental Methodology}

This study is built around comparing isochoric and isobaric heat release where three different cases are tested. Namely, Isochoric (ICC), Isobaric Low (IBLC) and Isobaric High (IBHC). Here, high and low refers to two different boost pressures. The IBLC reaches the same peak motored pressure (PMP) as the ICC while the IBHC reaches the same peak pressure. In general, the study is built on a previous metal engine study [20]. A similar geometry was used as compared to the metal studies. Therefore, similar injection strategies are used with similar fuel amounts. Here, n-heptane is used instead of diesel.

However, thermodynamic conditions in terms of pressure and temperature were adjusted to reach metal engine conditions (see Table 3 for specified values). The geometric compression ratio of the optical engine used is 15.4 while the effective compression ratio is 12.5 . The reduction from 15.4 to 12.5 is explained by blow-by losses. In the previous metal engine studies [20], a compression ratio of 17 was used.

With the higher blow-by and larger bowl volume (from other piston rings) of the optical engine, as compared to the metal engine, the boost pressure levels increased compared to previous studies [20]. Furthermore, intake heating was used based on reaching metal engine in-cylinder temperatures at the time of injection. Intake boost pressure and heating were based on the following equation:

$\int_{T_{0}}^{T_{c}} \frac{\gamma}{\gamma-1} \frac{d T}{T}=\ln \left(\frac{P_{c}}{P_{0}}\right)$

Where, $\gamma$ is the heat capacity ratio obtained from the polynomial correlations of air, $\mathrm{T}_{0}$ is the initial temperature and $\mathrm{P}_{0}$ is the initial pressure.

7/20/2015 
The detailed description of all cases is as follows:

Isochoric-A longer ignition delay was achieved for further premixing and thus a constant volume heat release leading to peak pressures of around 70 bar. The absolute intake pressure used for this case was 1.68 bar.

Isobaric Low - Same boost pressure levels as for the ICC with an injection strategy allowing close to isobaric combustion at around 50 bar in-cylinder pressure.

Isobaric High - This case was further boosted, to an absolute pressure of 2.42 bar, thus reaching a PMP of around 70 bar. The injection strategy with four injections allows close to isobaric combustion.

To summarize, the optical engine cases were designed to replicate the earlier metal engine experiments described above in order to explain phenomena concluded earlier. Differences between the optical engine and metal engine include a lower effective compression ratio along with changed heat losses when using quartz instead of metal for the piston. Here, these two differences have been compensated by adding intake heating and pressure boosting. Thus, the in-cylinder pressure and temperature at TDC are similar for the metal and optical engine cases.

\section{Results}

This section will describe the experimental data and observations of the study. The first part will contain results from earlier metal engine experiments to show performance measures. The second part examines the images obtained from the high-speed camera. Finally, the third part will consist of quantitative analyses of these images to further describe the observed phenomena.

\section{Earlier Metal Engine Experiments}

A summary of the main findings from earlier metal engine studies [20] is presented in this section. Figure 5 shows that the isobaric cases experience lower heat losses but with increased exhaust losses. Thus, the indicated efficiency remains similar to that of the CDC case for the Isobaric $\mathrm{H}$ case. This shows that with the same amount of fuel, isobaric combustion results in similar efficiencies as conventional diesel combustion.

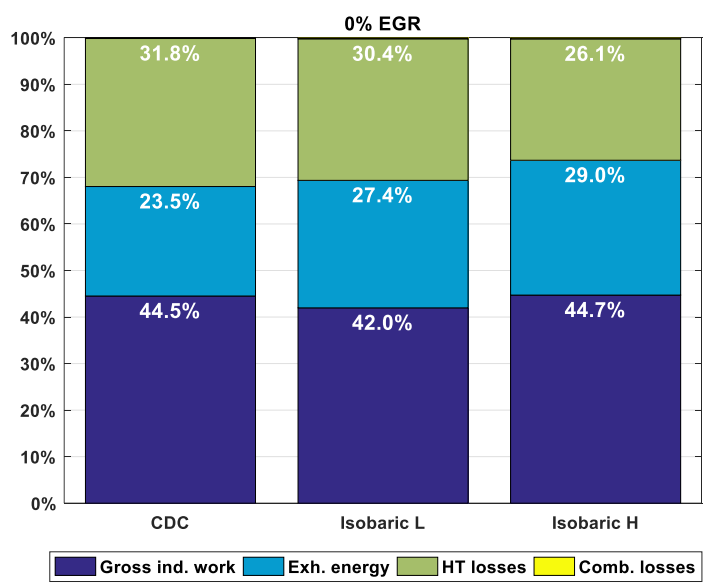

Figure 5, Efficiencies and losses from the metal engine experiments [20]

Page 4 of 10

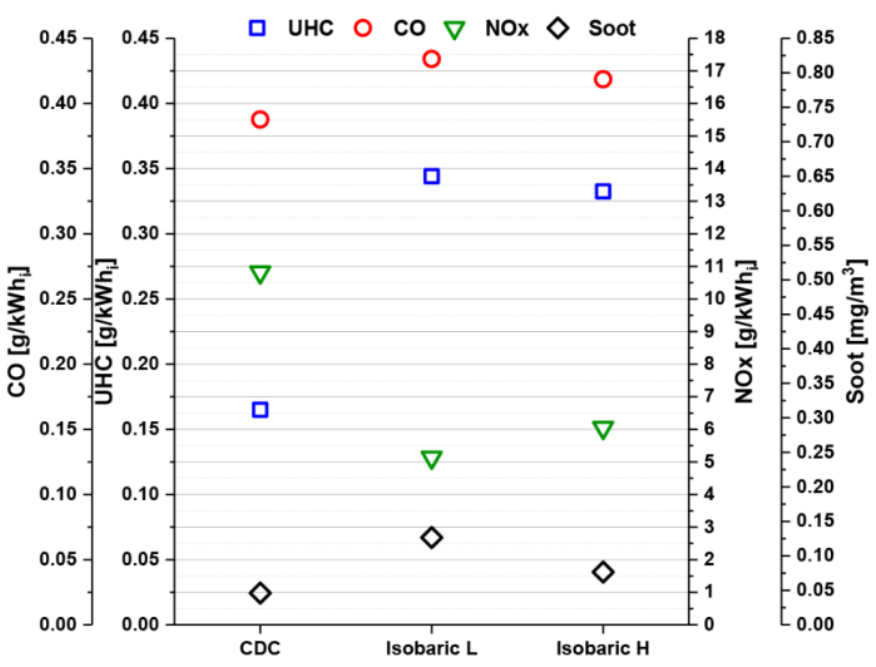

Figure 6, CO, UHC, NOx and soot emissions for the different metal engine experimental cases [20]

Figure 6 shows how soot, UHC and CO emissions increase when utilizing isobaric combustion. However, NOx levels decreased rapidly due to the lower in-cylinder temperature of the isobaric combustion.

To summarize, the earlier metal engine experiments showed how isobaric combustion can be used to keep efficiencies as high as conventional diesel combustion while reducing NOx levels.

\section{High-Speed Imaging}

As mentioned above, previous metal engine studies [20] described how low NOx, low heat losses but also high soot levels appear using an isobaric combustion approach. Here, a detailed explanation for such phenomena is reported.

Figure 7 shows the fast isochoric heat release. A long ignition delay is here established leading to large amounts of partially premixed combustion. The following rapid pressure rise leads to high-pressure fluctuations. It is also seen that much of the combustion takes place close to the edge of the bowl, suggesting an increased heat transfer. Hot zones at the walls have been proven to increase convective heat transfer in previous studies $[9,10]$. A substantial portion of injector dribbling is also observed at 9-22 CAD ATDC. For the IBLC, see Figure 8 , the four injections allow close to isobaric heat release. This results in a long combustion duration leaving less time for soot oxidation. The light intensity is strong for the IBLC suggesting high soot production. For heat losses, the optical images show fuel-rich hot zones close to the walls for the later CADs, 16-22 ATDC. However, much of the earlier combustion takes place away from the walls suggesting a heat transfer reduction. 


\begin{tabular}{|c|c|c|c|c|c|c|}
\hline Case & $\begin{array}{c}\text { Inj. Signal } \\
\text { [CAD ATDC] }\end{array}$ & $\begin{array}{l}\text { Inj. Duration } \\
{[\mu \mathrm{s}]}\end{array}$ & $\begin{array}{l}\text { Absolute Boost } \\
\text { Pressure [bar] }\end{array}$ & Intake Temp. $\left[{ }^{\circ} \mathrm{C}\right]$ & $\begin{array}{c}\text { Motored Peak } \\
\text { Temp. }\left[{ }^{\circ} \mathrm{C}\right]\end{array}$ & $\begin{array}{l}\text { Motored Peak } \\
\text { Pressure [bar] }\end{array}$ \\
\hline Isochoric & $-6,-3$ & 190,405 & 1.68 & 52 & 503 & 49 \\
\hline Isobaric Low & $-4,1,4,8.3$ & $\begin{array}{l}200,200, \\
220,300\end{array}$ & 1.68 & 52 & 505 & 49 \\
\hline Isobaric High & $-3,1,3.5,6.3$ & $\begin{array}{l}190,200, \\
200,270\end{array}$ & 2.42 & 52 & 508 & 68 \\
\hline $\begin{array}{l}\text { Isochoric (metal } \\
\text { engine) }\end{array}$ & $-6,-3$ & 190,405 & 1.00 & 19 & 537 & 49 \\
\hline $\begin{array}{l}\text { Isobaric Low } \\
\text { (metal engine) }\end{array}$ & $-4,1,4,8.3$ & $\begin{array}{l}200,200, \\
220,300\end{array}$ & 1.00 & 19 & 537 & 50 \\
\hline $\begin{array}{l}\text { Isobaric High } \\
\text { (metal engine) }\end{array}$ & $-3,1,3.5,6.3$ & $\begin{array}{l}190,200, \\
200,270\end{array}$ & 1.45 & 17 & 545 & 68 \\
\hline
\end{tabular}

Even if the IBHC uses a higher air-fuel ratio as compared to the IBLC, the combustion duration is similar (see Figure 9). The higher incylinder pressure, hence temperature, at the time of injection makes the ignition delay slightly shorter. For the IBHC, most of the combustion takes place close to the combustion chamber boundaries. Thus, the reduced heat losses seen for this case in earlier studies cannot be explained fully by this phenomenon. However, it should be noted that the time for wall heat exposure is seemingly short as a result of the shorter combustion compared to the IBLC.

The earlier metal engine studies [20] showed that the soot from the isobaric cases is higher than the conventional diesel case. Here, the explanation for such phenomena becomes clear. As seen in Figure 79, the luminosity from soot production in the IBHC and IBLC is higher as compared to the ICC. This is especially true for the IBLC. While there is little or no luminosity from soot later than 16 CAD ATDC for the ICC, the isobaric cases continue to experience high luminosity here. It should be noted that the pressure traces in Figure 7-9 are averaged from all the $3^{\text {rd }}$ fired cycle of each firing segment. However, the high-speed images are from the $24^{\text {th }}$ fired cycle which is deemed a representative cycle for combustion studies.

The high-speed images further show the effect of spraying into a flame which is the case when using the multiple injections of the isobaric cases, as seen in Figure 8 and Figure 9. An injection into a combusting zone means fast evaporation as well as a low air-fuel ratio for the liquid fuel. Thus, there is less time and lower amounts of air for mixing. This leads to soot production. Especially the IBLC suffers from this phenomenon, having a lower global air-fuel ratio due to the lower intake pressure. Thus, the high soot levels remain longer and leave shorter cycle time for post-oxidation. This is in line with the earlier studies discussed in the introduction section. For the IBHC, the soot problem is mitigated somewhat with the higher air-fuel ratio.

Another question raised here is the lower NOx levels for the isobaric cases as compared to the ICC. This can be explained by the longer combustion duration which resulted in lower in-cylinder temperature. Furthermore, the local air-fuel ratio is low for the later injections, as discussed above. Thus, the high-temperature zones are created with a Page 5 of 10 lack of air making NOx formation harder. The higher air-fuel ratio of the IBHC thus seems to have little or no effect on the NOx production. It should be noted that the normal trade-off between soot and NOx then remains with the isobaric heat addition.

For all cases, the first injection seems to have little or no effect on the heat release. This is not in line with the metal studies where the first injection acted as a pilot. A possible explanation is the use of n-heptane instead of diesel for this optical study. Furthermore, injector dribbling is observed, especially for the IBLC. This could possibly lead to fuelrich zones and thus soot production. However, this needs to be investigated further.

The remaining question is why we see the instable combustion for the ICC. Observations from the high-speed images confirmed this fact by showing a fluctuating flame. This leads to an unstable pressure trace, see Figure 7. Furthermore, higher turbulence causes higher convective heat losses. Here, the rise of luminosity and thus heat release is rapid between 5 and 7 CAD ATDC. The fast heat release causes rapid pressure rise and pressure waves inside the chamber. This will lead to higher noise levels for the engine and would be interesting to investigate further. Furthermore, higher heat losses will follow due to the break-down of the thermal boundary layer.

The higher heat losses of the ICC have been described and discussed briefly above. When comparing the different cases, the location of the hot zones can be investigated. For the ICC, the combustion occurs in the vicinity of the cylinder walls close to TDC.

Close to TDC, the volume is small leading to hot zones interfering with the head as well as the piston. This leads to high heat losses. The IBLC sustains later heat release meaning a smaller surface-to-volume ratio, and thus less flame/wall interaction, resulting in lower heat losses. However, the combustion duration is longer and thus the hot zones at the walls stay longer. It is also observed, from Figure 8, that much of the early combustion occurs away from the wall areas. 


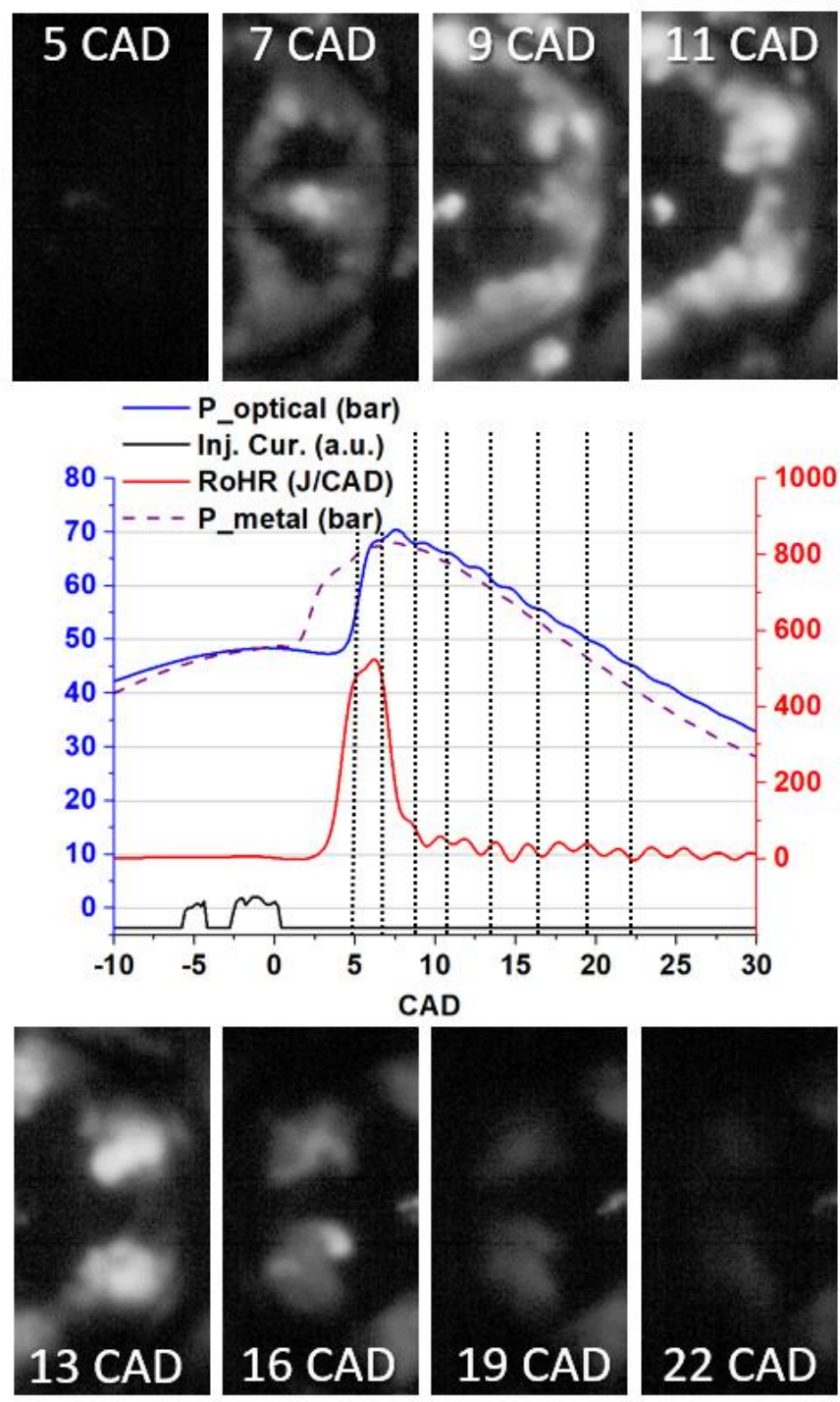

Figure 7, High-speed imaging along with in-cylinder pressure [bar], RoHR [J/CAD] and injection current [a.u.] for the Isochoric case.

The IBHC experiences similar behavior as the IBLC but with a shorter combustion duration (see Figure 9). Thus, heat losses are reduced due to the shorter exposure time of hot zones in the wall vicinity. A higher air-fuel ratio also leads to lower burned gas temperature although the pressure is higher. Furthermore, soot levels are lower for the IBHC as compared to the IBLC. Thus, less radiation from soot occurs and hence a lower amount of radiative heat losses.
The experimentally observed trends in the metal and optical engines with isochoric and isobaric combustions were successfully explained here. Below is a summary of the findings:

- Heat losses are reduced for isobaric combustion mainly by the lower in-cylinder temperature for both cases and also by the higher air-fuel ratio for the IBHC. A counter-effect for heat losses was found in terms of hot zones in the vicinity of the wall along with soot radiation for the isobaric cases.

- $\quad$ Regarding the soot levels, poor mixing was found the main reason for the high soot amounts for the isobaric cases. The IBLC experienced the highest soot levels due to its lower airfuel ratio compared to the IBHC.

- For NOx levels, the mixing was also found to be an explanation for the low levels for isobaric cases. The hightemperature zones created by the latter injections occurred in fuel-rich zones, meaning a low possibility of NOx production.

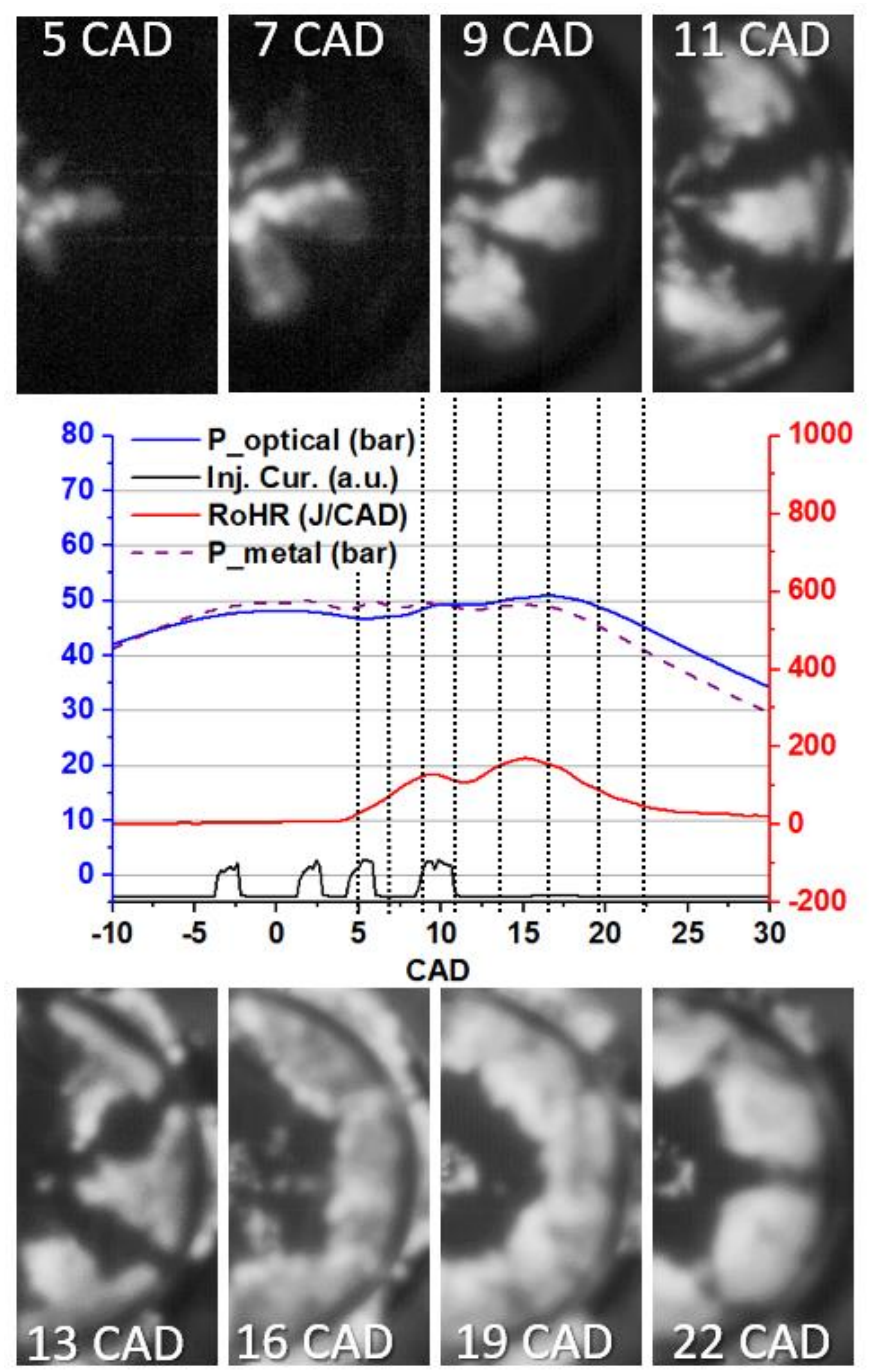

Figure 8, High-speed imaging along with in-cylinder pressure [bar], RoHR [J/CAD] and injection current [a.u.] for the Isobaric Low case 


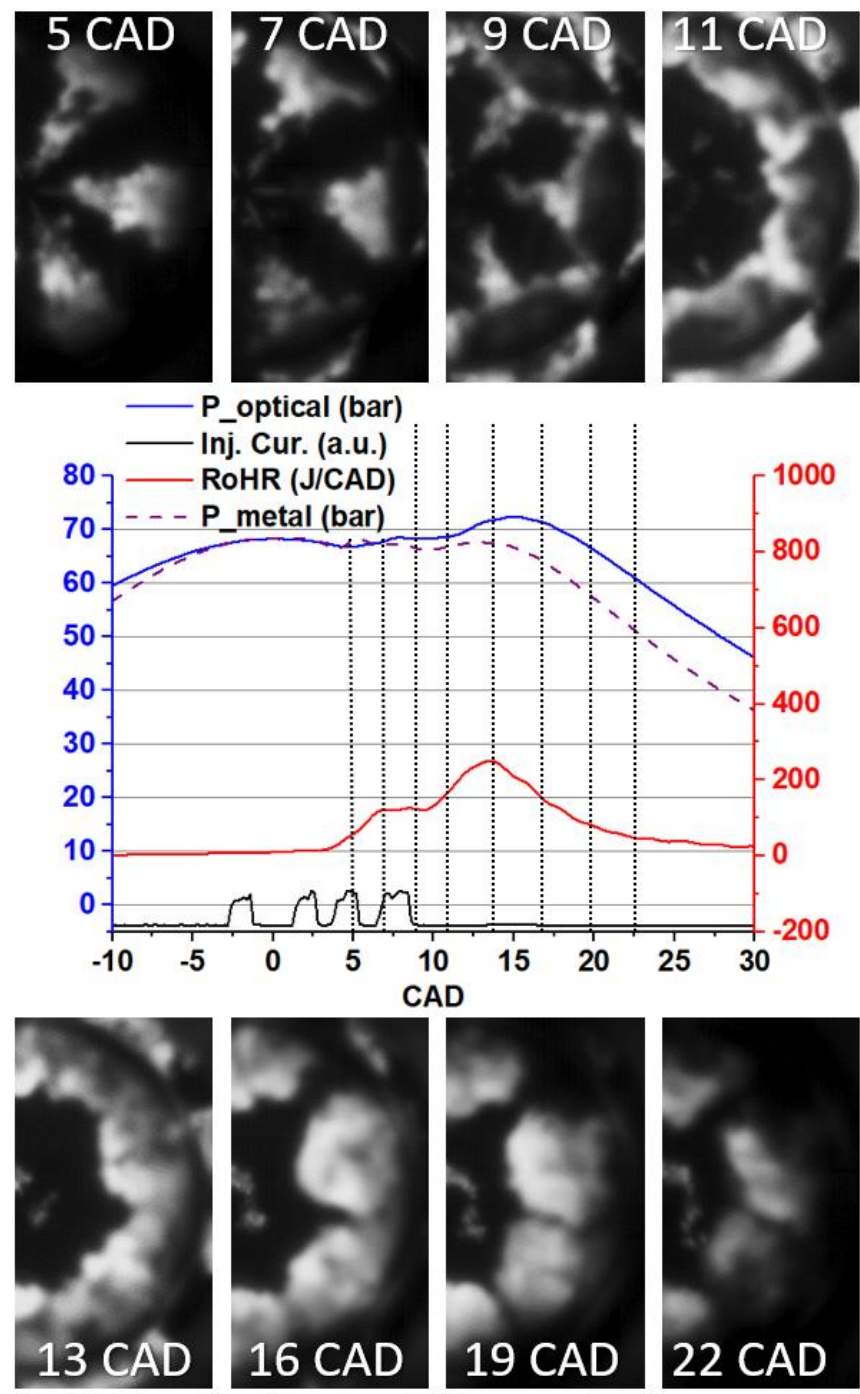

Figure 9, High-speed imaging along with in-cylinder pressure [bar], RoHR [J/CAD] and injection current [a.u.] for the Isobaric High case

\section{Average Chamber Luminosity Intensity}

A statistical analysis of the optical images provides a quantitative perspective of observed phenomena. Below, the statistical analysis of this study will be presented.

Figure 10 shows the spatially averaged light intensity in the chamber. Here, it is once again concluded that the ICC experiences lower intensities, showing lower levels of soot. The late high intensity of the IBLC confirms the high soot levels here which leave less time for soot oxidation (as the piston moves down, the global in-cylinder temperature reduces, hence the soot oxidation also slows down). The IBHC experiences high light intensities at later stages than the ICC. However, the signal significantly decrease after 20 CAD aTDC and completely disappears at $25 \mathrm{CAD}$ ATDC. The observations discussed here further explains the high soot levels of the isobaric cases, especially the IBLC, as observed in metal engine experiments.

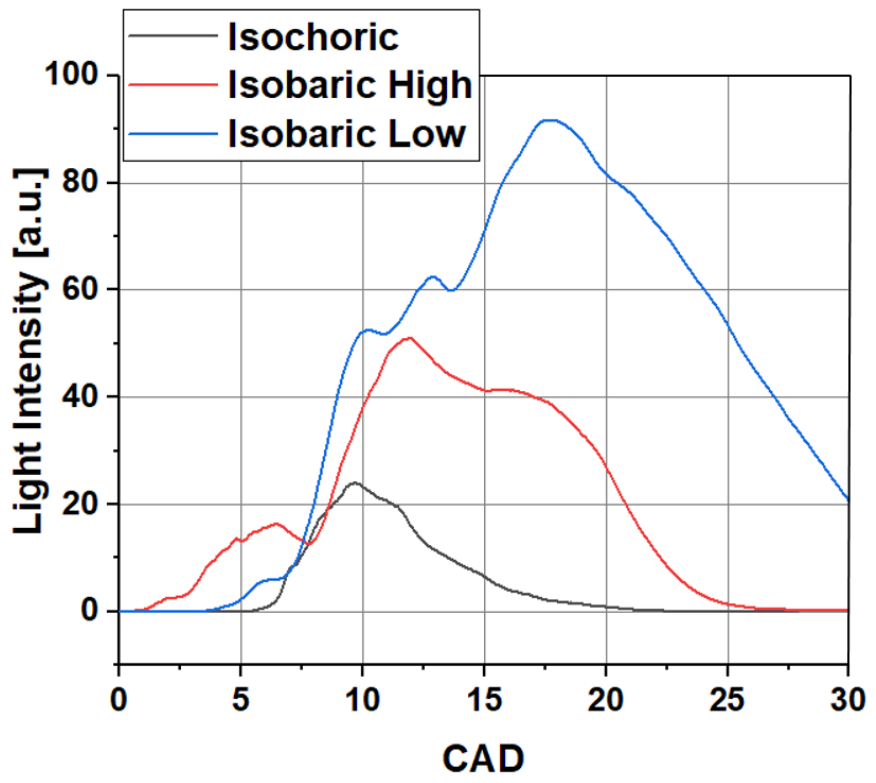

Figure 10, Average light intensity as a function of CAD for the different cases

The amount of luminous area is shown in Figure 11 where the cut-off intensity was set to 15 a.u. A binary system of the luminous area, as opposed to the black area, was established, showing the luminous twodimensional area. Relating to Figure 10, it is seen that the ICC, although having lower average intensity, still has a larger peak luminous area as compared to the IBHC. This suggests that the chamber area is not well utilized when using the multiple injections of the IBHC. As seen earlier in Figure 9, the majority of the flame is located in the vicinity of the chamber walls, suggesting high levels of heat transfer here.

The ICC also shows smaller differences from the IBLC as compared to the light intensity in Figure 10. This further confirms that, although the intensity is higher and more soot is formed, the chamber utilization is worse for the isobaric cases. It should also be noted that even at 30 CAD ATDC, the IBLC experiences the same luminosity area as the peak value for the IBHC. Thus, the high soot levels for this case are further confirmed. 


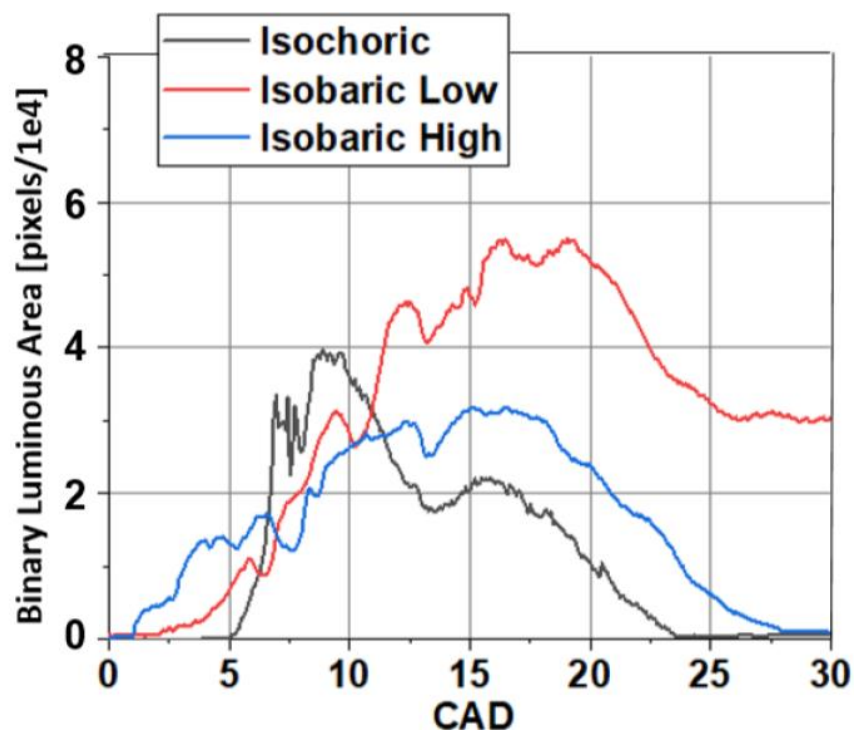

Figure 11, Binary luminosity area [a.u.] as seen from the bottom-view optical images

When observing the light intensity in a two-dimensional plane through one of the sprays, see Figure 12, it is seen that the early combustion occurs close to the injector for the IBLC. However, the later injections experience combustion close to the end of the bowl. This further confirms the longer penetration length of the late injections caused by the injection into an already fuel-rich zone. This phenomenon is not seen as much for the IBHC due to the higher global air-fuel ratio. At 10 CAD ATDC, two clear intensity peaks are observed for the IBHC. This further suggests that the later injection has more oxygen to burn compared to the IBLC. The ICC experience all its combustion close to the bowl edge following from the large quantity of fuel injected in a short time. Thus, high heat losses for this case are again confirmed.

From the results obtained and discussed above, it is clear that the isobaric cases experience poor mixing for the later injections. This is caused by liquid injection into a flame leading to fast evaporation combined with a lack of air and thus less mixing. Therefore, it is concluded that more degrees of freedom, in the form of injecting into different areas of the combustion chamber, are useful when utilizing the multiple injections of isobaric combustion. More injector holes combined with multiple injectors would thus be of use.

As discussed in the introduction section, metal experiments utilizing isobaric combustion show high potential in terms of stable combustion, efficiency and NOx emissions. However, a few challenges were highlighted in terms of high soot levels and understanding the combustion phenomena of the isobaric combustion. As a result of this optical study, a set of conclusions have been drawn that helps in comprehending and explain the performance measures seen in metal engine studies.

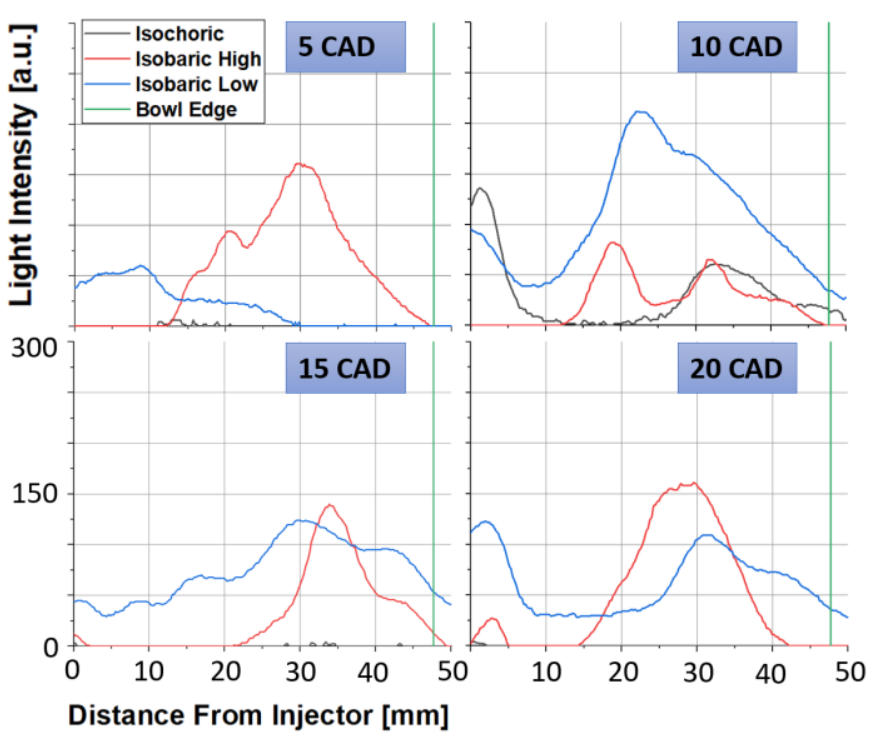

Figure 12, Light intensity [a.u.] at different locations in the chamber for 5, 10, 15 and 20 CAD ATDC

\section{Summary/Conclusions}

Optical experiments in a heavy-duty single-cylinder engine were conducted to investigate the combustion effects of isobaric heat release. Three major cases were compared, namely the Isochoric case, with heat release at constant volume, and the Isobaric Low and High cases, utilizing isobaric heat release at different boost levels.

- Optical engine experiments can help explain the trends of low NOx emissions and high efficiency observed in previous metal engine experiments

- The previously observed lower NOx in an all-metal engine with isobaric combustion can result from the lower local airfuel ratio as seen in the optical engine

- The multiple injections of the isobaric combustion result in liquid injection into a flame. This further results in fast evaporation and fuel-rich zones with little time for mixing. Thus, soot levels are increased.

- Poor chamber utilization results when using multiple injections with a majority of combustion happening in the vicinity of the combustion chamber walls. 


\section{References}

1. Nehmer, Daniel A., and Rolf D. Reitz. "Measurement of the effect of injection rate and split injections on diesel engine soot and NOx emissions." SAE transactions (1994): 1030-1041.

2. Johansson, B. "Combustion Engines", 2013

3. Caton, J.A., "Comparisons of Global Heat Transfer Correlations for Conventional and High Efficiency Reciprocating Engines," in ASME. Internal Combustion Engine Division Fall Technical Conference, ASME 2011 Internal Combustion Engine Division Fall Technical Conference, 327-337, doi:10.1115/ICEF201160017.

4. Sjöberg, M. and Dec, J., "Combined Effects of Fuel-Type and Engine Speed on Intake Temperature Requirements and Completeness of Bulk-Gas Reactions for HCCI Combustion" SAE Technical Paper 2003-01-3173, 2003, doi:10.4271/2003-013173.

5. Christensen, M. and Johansson, B., "Supercharged Homogeneous Charge Compression Ignition (HCCI) with Exhaust Gas Recirculation and Pilot Fuel," SAE Technical Paper 2000-01-1835, 2000, https://doi.org/10.4271/2000-01$\underline{1835}$.

6. Richter, M., Engström, J., Franke, A., Aldén, M. et al., "The Influence of Charge Inhomogeneity on the HCCI Combustion Process," SAE Technical Paper 2000-01-2868, 2000, https://doi.org/10.4271/2000-01-2868.

7. Okamoto, T. and Uchida, N., "New Concept for Overcoming the Trade-Off between Thermal Efficiency, Each Loss and Exhaust Emissions in a Heavy Duty Diesel Engine," SAE Int. J. Engines 9(2):2016, doi:10.4271/2016-01-0729.

8. Enya, K. and Uchida, N., "Improvement in Thermal Efficiency of a Diesel Engine by Homogenized Flame Distribution," SAE Technical Paper 2019-24-0166, 2019, https://doi.org/10.4271/2019-24-0166.

9. Nyrenstedt, G., Al Turkestani, T., Im, H., and Johansson, B., "CFD Study of Heat Transfer Reduction Using Multiple Injectors in a DCEE Concept" SAE Technical Paper 2019-01-0070, 2019, doi:10.4271/2019-01-0070.

10. Nyrenstedt, G., Im, H., Andersson, A., and Johansson, B., "Novel Geometry Reaching High Efficiency for Multiple Injector Concepts" SAE Technical Paper 2019-01-0246, 2019, doi:10.4271/2019-01-0246.

11. Nyrenstedt, G., Watanabe, K., Enya, K., Shi, H. et al., "Thermal Efficiency Comparison of Different Injector Constellations in a CI Engine," SAE Technical Paper 2019-24-0172, 2019, https://doi.org/10.4271/2019-24-0172.

12. Lam, N., Tunestal, P., and Andersson, A., "Simulation of System Brake Efficiency in a Double Compression-Expansion Engine-Concept (DCEE) Based on Experimental Combustion Data," SAE Technical Paper 2019-01-0073, 2019, https://doi.org/10.4271/2019-01-0073.

13. Lam, N., Andersson, A., and Tunestal, P., "Double Compression Expansion Engine Concepts: Efficiency Analysis over a Load Range," SAE Technical Paper 2018-01-0886, 2018, https://doi.org/10.4271/2018-01-0886.

14. Lam, N., Tuner, M., Tunestal, P., Andersson, A. et al., "Double Compression Expansion Engine Concepts: A Path to High Efficiency," SAE Int. J. Engines 8(4):1562-1578, 2015, https://doi.org/10.4271/2015-01-1260.

15. AlRamadan, A., Ben Houidi, M., Aljohani, B., Eid, H. et al., "Compression Ratio and Intake Air Temperature Effect on the Fuel Flexibility of Compression Ignition Engine," SAE Technical Paper 2019-24-0110, 2019, https://doi.org/10.4271/2019-24-0110.
16. Cengel, Y. A., Boles, M. A., Kanoglu, M., "Thermodynamics An Engineering Approach", $9^{\text {th }}$ edition, 2018

17. Heywood, J. B., "Internal Combustion Engine Fundamentals", 1988

18. Hoshi, M. "Reducing friction losses in automobile engines." Tribology international 17, no. 4 (1984): 185-189.

19. Bhavani Shankar, V., Lam, N., Andersson, A., and Johansson, B., "Optimum Heat Release Rates for a Double Compression Expansion (DCEE) Engine," SAE Technical Paper 2017-010636, 2017, https://doi.org/10.4271/2017-01-0636.

20. Babayev, R., Ben Houidi, M., Andersson, A., and Johansson, B., "Isobaric Combustion: A Potential Path to High Efficiency, in Combination with the Double Compression Expansion Engine (DCEE) Concept," SAE Technical Paper 2019-01-0085, 2019, https://doi.org/10.4271/2019-01-0085.

\section{Contact Information}

\section{Gustav Nyrenstedt \\ Ph.D. Candidate}

Clean Combustion Research Center (CCRC)

King Abdullah University of Science and Technology (KAUST)

23955-6900 Thuwal, Saudi Arabia

Phone no - +966 (0)56 $045 \quad 8328$

gustav.nyrenstedt@kaust.edu.sa

\section{Acknowledgments}

The paper is based upon work supported by Saudi Aramco Research and Development Center FUELCOM3 program under Master Research Agreement Number 6600024505/01. FUELCOM (Fuel Combustion for Advanced Engines) is a collaborative research undertaking between Saudi Aramco and KAUST intended to address the fundamental aspects of hydrocarbon fuel combustion in engines, and develop fuel/engine design tools suitable for advanced combustion modes. Furthermore, the authors would like to thank Arne Andersson at Volvo AB for his valuable inputs. Finally, the authors would like to thank MESA Engine Solutions for their cooperation and valuable input for our engines.

\section{Definitions/Abbreviations}

$\begin{array}{ll}\text { ATDC } & \text { After Top Dead Center } \\ \text { CAD } & \text { Crank Angle Degree } \\ \text { CI } & \text { Compression Ignition } \\ \text { DCEE } & \begin{array}{l}\text { Double Compression } \\ \text { Expansion Engine }\end{array} \\ \text { HCCI } & \begin{array}{l}\text { Homogenous Charge } \\ \text { Compression Ignition }\end{array} \\ \text { IBHC } & \text { Isobaric High Case } \\ \text { IBLC } & \text { Isobaric Low Case } \\ \text { ICC } & \text { Isochoric Case }\end{array}$

Page 9 of 10 
LTC

NOx

PMP

RoHR

Soot
Low-Temperature

Combustion

Nitrogen Oxides

Peak Motored Pressure

Rate of Heat Release

Different types of particulate matter lumped together
TDC

UHC

Unburned Hydrocarbons 